\title{
A produção audiovisual da série de filmes O desenho conectando conhecimentos: a pesquisa, o ensino e a prática do desenho em debate.
}

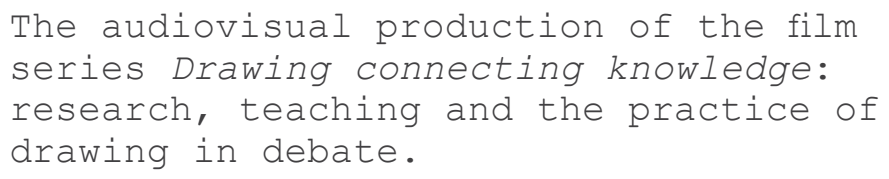

Anelise Zimmermann ${ }^{1}$

\footnotetext{
Anelise Zimmermann - Doutora em Design (UFPE), com doutorado sanduíche (CNPq) na University of the Arts London, Reino Unido e Mestre em Artes Visuais pela UDESC. É professora efetiva do Departamento de Design da UDESC e integrante dos Grupo de Pesquisa RIDE - Rede Internacional Design/Educação (UFPE) e Literalise (UFSC) com pesquisas voltadas ao ensino do desenho, design de informação e narrativas visuais na literatura infantil.

Lattes: http://lattes.cnpq.br/8548816949021546

E-mail: anelise.zimmermann@gmail.com

Link: www.pesquisaemdesenho.com
} 


\title{
Resumo
}

A série de filmes $O$ desenho conectando conhecimentos foi produzida a partir de entrevistas com educadores, pesquisadores, artistas e designers do Reino Unido, os quais contam sobre suas experiências no ensino, pesquisa e prática do desenho a partir de perspectivas contemporâneas e interdisciplinares. O projeto teve como objetivo ampliar o debate sobre o desenho por meio da adaptação da pesquisa acadêmica ao formato audiovisual, com sua disponibilização online, aproximando diferentes públicos e instituições.

\section{Palavras-chave}

desenho; ensino; pesquisa.

\begin{abstract}
The film series Drawing connecting knowledge presents interviews with educators, researchers, artists, designers, from the United Kingdom, sharing their experiences concerning drawing practice, research, and an education based on a contemporary and interdisciplinary approach. This project aimed to broaden the debate on drawing by adapting the academic research to an audiovisual production, which became available online, bringing together diverse audiences and institutions.
\end{abstract}

\section{Keywords}

drawing; education; research. 
A série de filmes $O$ desenho conectando conhecimentos foi produzida a partir de entrevistas com educadores, pesquisadores, artistas e designers no Reino Unido, durante o período de doutorado sanduíche de Zimmermann (2016) na University of the Arts London no Reino Unido. Os filmes têm como objetivo registrar e compartilhar parte das experiências da pesquisadora nesse período, bem como ampliar as possibilidades do debate sobre o ensino do desenho por abordagens contemporâneas e interdisciplinares, aproximando a escola, a formação superior, a pesquisa e a prática profissional em diferentes cenários. A proposição da elaboração dos filmes surgiu a partir de conversas com Farthing, seu supervisor naquela instituição, o qual possui uma produção audiovisual abrangendo reflexões e práticas em pintura e desenho em parceria com instituições como a Royal Academy of Arts, a University of Oxford e a University of the Arts London, estando os filmes disponíveis online gratuitamente (FARTHING, 2020).

Visto que a proposta inicial da pesquisa incluía a análise do cenário do ensino e prática do desenho no Reino Unido com a coleta de dados por entrevistas, essa proposta foi ampliada a conversas gravadas em vídeo para a produção dos filmes. Foram entrevistados onze profissionais diferentes, num período de aproximadamente 6 meses. Cada entrevista teve duração média de 40 minutos e abordaram os seguintes questionamentos: Como definir o que é desenho? Quais as funções do desenho além das artes? Como pensar o ensino do desenho hoje? Como avaliar um "bom" desenho? Como o desenho participa do processo criativo? Como o desenho pode conectar conhecimentos e áreas? Quais as propostas de pesquisa em desenho?

Como pensar o desenho na escola?

Após a gravação das entrevistas, o material foi agrupado por temas e editado, gerando sete filmes com duração de vinte a trinta minutos, todos legendados em português. Os filmes foram lançados em 2017 pela Editora da Universidade do Estado de Santa Catarina, com cadastro na Biblioteca Nacional (ISBN) e hospedados em endereço online com acesso gratuito, com versão em português e inglês. Junto aos filmes foram incluídas a descrição de cada episódio e informações sobre os entrevistados, resumidos a seguir:

Episódio 1 - A pesquisa em desenho: Nesse filme o artista e pesquisador Stephen Farthing aborda a importância das pesquisas em desenho e dos estudo de uma definição e taxonomias para o desenho. Farthing também apresenta perspectivas da pesquisa em desenho pelo desenho. Stephen Farthing recebeu a cátedra de Desenho da University of Artes London (UAL) entre os anos de 2004-2016, foi também um dos líderes Centre for Drawing, centro de estudos em desenho na mesma instituição, além de ser artista e membro da Royal Academy of Arts de Londres.

Episódio 2 - O desenho em uma abordagem interdisciplinar: Neste espisódio, Kelly Chorpening e Miraj Ahmed, artistas e professores no Bacharelado em Desenho da UAL e Tony Thatcher, líder do Programa Master em Coreografia no Trinity Laban Conservatoire of Music and Dance de Londres, falam sobre projetos desenvolvidos em conjunto, interligando a prática do desenho à arquitetura e à dança.

Episódio 3 - O ensino e a pesquisa em desenho: Neste filme, Simon Betts, 
Diretor da Wimbledon College of Arts (UAL), pesquisador e um dos membros do Centre for Drawing, fala sobre a elaboração de currículos em desenho e novas perspectivas para a pesquisa na área.

Episódio 4 - O ensino e a prática em desenho: Sarah Pickstone e Paul GopalChowdhury, artistas e professores da Royal Drawing School, contam sobre suas experiências em desenho na formação em artes e discutem questões referentes à prática, interdisciplinaridade, aprendizagem e ensino do desenho. Em seguida, Oliver Sullivan, cantor lírico, conta sobre sua experiência como estudante de desenho na mesma instituição e como essa experiência é incorporada no seu cotidiano.

Episódio 5 - Educação em desenho: Nesse filme, Eileen Adams relata seu percurso no ensino e formação de educadores em desenho e sobre sua participação em The Campaign for Drawing, evento anual que reúne universidades, escolas e museus com o objetivo de promover novas abordagens no ensino e a prática do desenho no Reino Unido.

Episódio 6 - O desenho no Design de Informação: Tim Fendley, um dos diretores do estúdio Applied Wayfinding de Londres, conta sobre os usos do desenho no processo criativo dos projetos de design de informação Legible London (projeto de wayfinding da cidade de Londres) e Walking Rio (projeto de sinalização do Rio de Janeiro para os Jogos Olímpicos de 2016).

Episódio 7 - O desenho no processo projetual: Neste episódio, os designers Benjamin Baker e Mabel Lazzarini falam sobre suas experiências com o desenho na formação em design e no meio profissional, destacando aspectos que consideram importantes em sua aprendizagem.

O pré-lançamento dos vídeos foi feito em 2016, com palestra da pesquisadora sobre a experiência dessa produção, seguida da abertura de exposição de desenhos ilustrativos dos temas levantados nos filmes. A exposição foi organizada em conjunto com os estudantes do Curso de Design Gráfico da Universidade do Estado de Santa Catarina, inscritos na disciplina de Laboratório de Desenho 2, a qual é ministrada pela pesquisadora. Além do material exposto, foi também incluído um painel interativo no qual o público foi convidado a desenhar, gerando reflexões e soluções por meio do desenho para um tema lançado. O registro do lançamento e exposição consta também no endereço online dos filmes.

Em 2019 a série de filmes recebeu o Prêmio Destaque na 13ª Bienal Brasileira de Design Gráfico na categoria Pensando o Design/Documentários, por seu conteúdo e formato de apresentação. Vale ressaltar que essa categoria foi incluída na premiação a partir dessa edição da Bienal, compreendendo também o formato de podcasts/ videocasts. Todos os projetos premiados no evento foram expostos no Museu Oscar Niemeyer de Curitiba, com visitação aberta ao público e gratuita, no período de 29 de novembro a 16 de dezembro de 2019. Os trabalhos também encontram-se expostos na página online do evento (BIENAL ADG, 2019).

Por fim, os filmes também têm sido utilizados como material didático nas disciplinas de desenho ministradas pela pesquisadora, servindo como proposições 
para reflexões quanto aos seus conteúdos, incluindo discussões coletivas sobre o processo de ensino/aprendizagem do desenho na escola e meio acadêmico e as funções e importância do desenho no meio profissional.

Concluindo, toda a experiência desse projeto serviu como aprendizado na elaboração, pós-produção e divulgação de conteúdos audiovisuais pensados para o compartilhamento da produção acadêmica, ampliado as possibilidades de acesso além dos formatos tradicionais de produções textuais. Além disso, o projeto também aproximou os pesquisadores, educadores, estudantes, profissionais das artes e design envolvidos, corroborando a importância do debate sobre o tema e o caráter interdisciplinar do desenho, como menciona o próprio título da série.

\section{Referências:}

BIENAL ADG. 13 ${ }^{a}$ Bienal Brasileira do Design Gráfico. Selecionados. Disponível em: <https://bienaladg.org.br>. Acesso em: 20 jul. 2020.

FARTHING, Stephen. Videolinks. 2020. Disponível em: http://stephenfarthing.co.uk. Acesso em: 20 jul. 2020.

O desenho conectando conhecimentos. Anelise Zimmermann. Londres/Florianópolis, Editora UDESC. 1 DVD (20 min), MP4, color. Português/Inglês, 2018. Disponível em: <www. pesquisaemdesenho.com>. Acesso em: 20 jul. 2020.

ZIMMERMANN, Anelise. O ensino do desenho na formação em Design Gráfico: uma abordagem projetual e interdisciplinar. Tese Doutorado. Universidade Federal de Pernambuco, 2016.

ZIMMERMANN, Anelise. Pesquisa em desenho. 2017. Disponível em: www. pesquisaemdesenho.com. Acesso em: 20 jul. 2020.

Recebido em 30 de julho de 2020.

Aprovado em 08 de agosto de 2020. 